\title{
Pengembangan Modul Pembelajaran Biologi Berbasis SQ4R sebagai Bahan Belajar untuk Siswa SMA
}

\author{
Nurul Zakiyatin Nisak, Murni Saptasari, Aloysius Duran Corebima \\ Pendidikan Biologi-Universitas Negeri Malang
}

\begin{tabular}{l}
\hline \hline INFO ARTIKEL \\
\hline Riwayat Artikel: \\
Diterima: 20-02-2019 \\
Disetujui: $21-03-2019$ \\
\hline
\end{tabular}

\section{Kata kunci:}

biological module; SQ4R model; teaching materials; high school student; modul biologi; model SQ4R;

bahan ajar; siswa SMA

\author{
Alamat Korespondensi: \\ Nurul Zakiyatin Nisak \\ Pendidikan Biologi \\ Universitas Negeri Malang \\ Jalan Semarang 5 Malang \\ E-mail: nurulznisa@gmail.com
}

\section{ABSTRAK}

\begin{abstract}
This study was aimed to develop a valid biology learning module based on SQ4R model as a learning material for high school students. This study adapted the ADDIE model. The validity of the module was known from the expert validation scores and student responses. The results showed that the validation scores from module expert was $85.45 \%$ (valid), material experts was $97.5 \%$ (very valid), field practitioners was $98.1 \%$ (very valid) and very good student responses with score of $94.96 \%$. Based on these results, it can be concluded that the developed biology learning module based on SQ4R model is classified as valid and practical to be used in the learning process as learning material for high school students.
\end{abstract}

\begin{abstract}
Abstrak: Tujuan penelitian ini yakni untuk mengembangkan modul pembelajaran biologi berbasis model SQ4R yang layak digunakan sebagai bahan belajar untuk siswa SMA. Penelitian ini mengadaptasi model pengembangan ADDIE. Kelayakan modul diketahui dari skor validasi para ahli dan respon siswa. Hasil penelitian menunjukkan perolehan skor validasi ahli bahan ajar sebesar 85,45\% (layak), ahli materi sebesar 97,5\% (sangat layak), praktisi lapangan sebesar $98,1 \%$ (sangat layak) serta respon siswa yang sangat baik dengan perolehan nilai sebesar $94,96 \%$. Berdasarkan hasil tersebut, dapat disimpulkan bahwa modul pembelajaran Biologi berbasis model SQ4R yang dikembangkan tergolong layak dan praktis digunakan dalam proses pembelajaran sebagai bahan belajar untuk siswa SMA.
\end{abstract}

Pendidikan pada hakikatnya merupakan usaha sadar yang dengan sengaja dirancang agar siswa dapat mengembangkan potensi diri melalui pembelajaran. Pembelajaran dapat berjalan dengan lancar jika didukung komponen-komponen pembelajaran yaitu siswa, guru, kompetensi dasar, media dan fasilitas belajar, sumber belajar, serta materi atau bahan ajar (Shaleh, 2006). Bahan ajar sangat penting dalam mendukung pembelajaran. Penggunaan bahan ajar dalam pembelajaran dapat memfasilitasi siswa belajar dan mempermudah guru dalam melakukan pembelajaran (Departemen Pendidikan Nasional, 2008). Terlepas dari pentingnya bahan ajar dalam mendukung kegiatan pembelajaran, permasalahan yang berkaitan dengan bahan ajar masih terjadi. Berdasarkan hasil analisis kebutuhan pada bulan Mei 2018 di SMA Negeri 2 Bandar Lampung melalui pemberian angket pada 70 siswa kelas XI ditemukan bahwa tidak semua siswa memiliki buku paket Biologi kelas XI. Siswa yang mempelajari berbagai buku juga mengalami kebingungan karena adanya perbedaan konsep pada buku-buku yang dipelajari. Siswa juga mengalami kesulitan dalam mempelajari buku karena gambar dan penjelasan konsepnya sangat kompleks dan tidak mudah dipahami. Siswa menjadi kesulitan dalam mempelajari Biologi karena banyak hafalan dan istilah yang sulit.

Berdasarkan hasil analisis kebutuhan, bahan ajar berupa modul pembelajaran perlu untuk dikembangkan. Pemilihan modul dilakukan dengan alasan memfasilitasi siswa dalam belajar secara mandiri. Keunggulan modul pembelajaran yaitu fokus pada kemampuan individual siswa (Mulyasa, 2006). Modul yang dikembangkan yaitu modul pembelajaran Biologi berbasis model SQ4R. Model pembelajaran SQ4R dipilih karena tergolong sebagai model pembelajaran yang berpusat pada siswa (Rustina, 2014; Shoimin, 2014; Arhasy dkk., 2015; Rasjid, 2015). Model pembelajaran SQ4R terbukti efektif digunakan dalam pembelajaran (Glass \& Zygouris-Coe, 2005; Rahayu dkk., 2015; Rivan dkk., 2017), termasuk dalam pembelajaran Biologi (Rasjid, 2015; Dewi, 2016; Swari dkk., 2016). Model pembelajaran SQ4R efektif digunakan untuk mempelajari materi (Syah, 2013; Trianto, 2013). Kelebihan model pembelajaran SQ4R salah satunya yakni materi yang dipelajari siswa akan melekat lebih lama (Shoimin, 2014). Modul dikembangkan melalui tahapan validasi oleh para ahli dan uji coba pendahuluan agar selanjutnya dapat diterapkan dalam proses pembelajaran. Penelitian ini bertujuan untuk mengembangkan modul SQ4R yang layak sebagai bahan belajar untuk siswa SMA. 


\section{METODE}

Penelitian ini adalah penelitian pengembangan dengan model ADDIE dari Branch (2009) yang terdiri dari lima tahap, yaitu analyze, design, develop, implement, dan evaluate. Tahap analyze dilakukan melalui wawancara guru Biologi SMAN 2 Bandar Lampung dan pemberian angket analisis kebutuhan pada siswa. Tahap design dilakukan dengan membuat rancangan modul. Tahap develop dilakukan dengan mengembangkan modul sesuai rancangan dan melakukan validasi modul. Tahap implement dilakukan dengan menerapkan. Tahap evaluate dilakukan dengan melakukan evaluasi hasil yang diperoleh pada tiap tahapan.

Validator dalam penelitian ini yaitu dosen Biologi UM sebagai ahli bahan ajar dan ahli materi serta guru Biologi SMAN 2 Bandar Lampung sebagai praktisi lapangan. Subjek penelitian ini meliputi 15 siswa SMAN 2 Bandar Lampung. Instrumen yang digunakan, yakni lembar validasi modul dan angket respons siswa terhadap modul. Jenis data yakni data kualitatif dan data kuantitatif. Data kualitatif yakni saran dan komentar validator (pada lembar validasi) dan siswa (pada angket respons siswa). Data kuantitatif yakni skor dari lembar validasi dan skor dari angket respon siswa. Data kuantitatif hasil validasi modul dianalisis menggunakan rumus:

$$
\mathrm{V}=\frac{\sum X}{\sum X i} \times 100 \%
$$

Keterangan:

$$
\begin{array}{ll}
\mathrm{V} & =\text { persentase kelayakan } \\
\sum \mathrm{X} & =\text { jumlah skor keseluruhan jawaban per butir } \\
\sum \mathrm{Xi} & =\text { skor maksimal }
\end{array}
$$

Kriteria kelayakan modul berdasarkan hasil perhitungan terdapat pada tabel 1.

Tabel 1. Kriteria Penilaian Kelayakan Modul

\begin{tabular}{cl}
\hline Persentase (\%) & \multicolumn{1}{c}{ Keterangan } \\
\hline $86-100$ & Sangat layak digunakan, tanpa revisi \\
$71-85$ & Cukup layak digunakan, namun perlu direvisi \\
$51-70$ & Kurang layak digunakan karena perlu revisi \\
$0-50$ & Tidak layak digunakan dan perlu revisi total \\
\hline
\end{tabular}

Sumber: diadaptasi dari Akbar (2013)

Data kuantitatif hasil angket respon siswa dianalisis menggunakan rumus sebagai berikut.

$$
\mathrm{P}=\frac{\sum X}{\sum X i} \times 100 \%
$$

Keterangan:

$\mathrm{P} \quad=$ presentase respon siswa

$\sum \mathrm{X}=$ jumlah skor skor keseluruhan jawaban per butir

$\sum \mathrm{Xi} \quad=$ skor maksimal per butir

Kriteria respon siswa berdasarkan hasil perhitungan dengan rumus di atas dapat dilihat pada tabel 2.

Tabel 2. Kriteria Respon Siswa terhadap Modul

\begin{tabular}{cc}
\hline Persentase (\%) & Keterangan \\
\hline $82-100$ & Sangat baik \\
$62-81$ & Baik \\
$42-61$ & Kurang baik \\
$0-41$ & Tidak baik \\
\hline
\end{tabular}

Sumber: diadaptasi dari Akbar (2013) 


\section{HASIL}

Produk yang dihasilkan dalam penelitian ini yaitu modul Biologi berbasis model SQ4R untuk siswa SMA kelas XI. Modul dikembangkan dalam tiga jilid. Modul jilid pertama membahas tentang jaringan hewan, jilid kedua membahas tentang sistem gerak, sedangkan jilid ketiga membahas tentang sistem peredaran darah. Tampilan cover modul dapat dilihat pada gambar 1. Modul divalidasi oleh ahli bahan ajar, ahli materi, dan praktisi lapangan, kemudian dilakukan uji coba pendahuluan terhadap modul kepada 15 siswa.

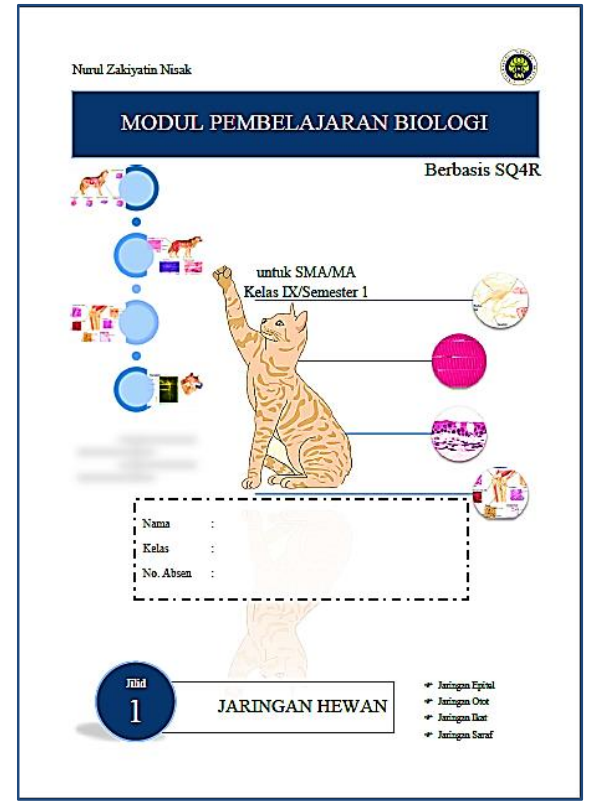

(a)

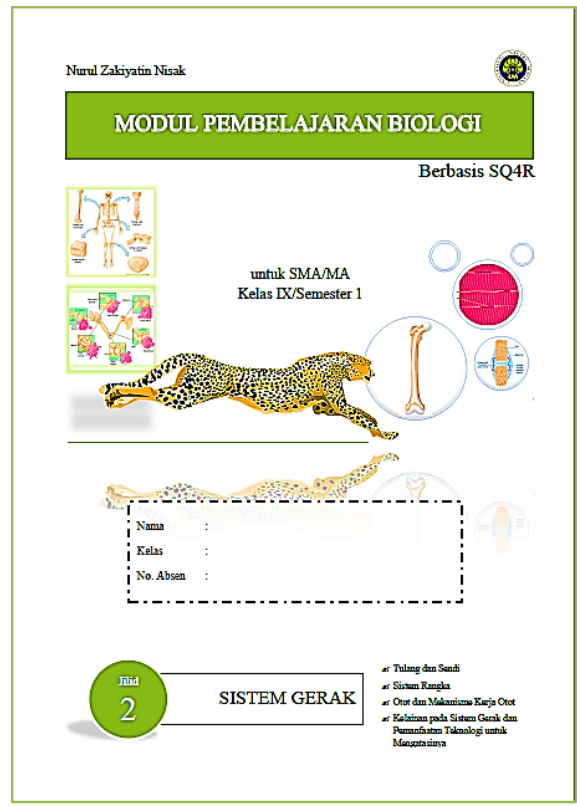

(b)

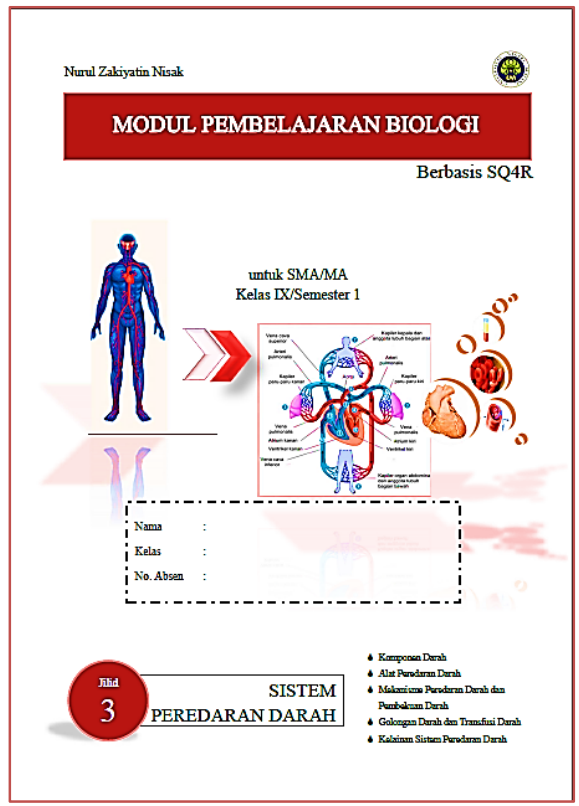

(c)

Gambar 1. Cover Modul: (a) Jilid 1; (b) Jilid 2; (c) Jilid 3

Validasi Ahli Bahan Ajar

Hasil validasi modul oleh ahli bahan ajar menunjukkan nilai kelayakan modul untuk aspek self instructional, self contained, stand alone, adaptive, dan user friendly secara berturut-turut sebesar $85,71 \%, 80 \%, 100 \%, 80 \%$, dan $80 \%$. Modul yang dikembangkan memiliki nilai kelayakan modul sebesar $85,45 \%$ dengan kriteria layak. Hasil validasi ahli bahan ajar ditampilkan pada tabel 3 .

Tabel 3. Hasil Validasi Modul oleh Ahli Bahan Ajar

\begin{tabular}{clcc}
\hline No. & Aspek yang Dinilai & Presentasi & Kriteria \\
\hline 1. & Self Instructional & $85,71 \%$ & Layak \\
2. & Self Contained & $80 \%$ & Layak \\
3. & Stand Alone & $100 \%$ & Sangat Layak \\
4. & Adaptive & $80 \%$ & Layak \\
5. & User friendly & $80 \%$ & Layak \\
\hline & Jumlah & $85,45 \%$ & Layak \\
\hline
\end{tabular}

Saran dan komentar yang diberikan oleh ahli bahan ajar, antara lain (1) petunjuk penggunaan modul sebaiknya diperbaiki; (2) kegiatan pembelajaran SQ4R pada tahap question perlu diberikan contoh pertanyaan rasional diubah menjadi pengantar; (3) pada beberapa Tugas Mandiri perlu ada perbaikan; (4) beberapa soal evaluasi perlu diperhatikan lagi.

\section{Validasi Ahli Materi}

Hasil validasi modul oleh ahli materi menunjukkan nilai kelayakan modul untuk seluruh aspek sebesar 97,5\% dengan kriteria sangat layak. Hasil validasi ahli materi ditampilkan pada tabel 4. 
Tabel 4. Hasil Validasi Modul oleh Ahli Materi

\begin{tabular}{|c|c|c|c|}
\hline No. & Aspek yang Dinilai & Persentase & Kriteria \\
\hline 1. & Organisasi Materi & $95 \%$ & Sangat Layak \\
\hline 2. & Kedalaman/Keluasan Materi & $100 \%$ & Sangat Layak \\
\hline 3. & Akurasi Materi & $100 \%$ & Sangat Layak \\
\hline 4. & Kemutakhiran Materi & $100 \%$ & Sangat Layak \\
\hline \multirow[t]{2}{*}{5.} & Materi Kontektual & $100 \%$ & Sangat Layak \\
\hline & Jumlah & $97,5 \%$ & Sangat Layak \\
\hline
\end{tabular}

Saran dan komentar yang diberikan oleh ahli materi, antara lain (1) beberapa gambar perlu lebih diperjelas ketajamanannya; (2) ada beberapa kalimat yang perlu disusun ulang agar siswa lebih mudah memahami; (3) pada bagian "Tahukah Kamu?" sebaiknya dicantumkan sumber rujukannnya.

\section{Validasi Ahli Praktisi Lapangan}

Aspek yang dinilai oleh praktisi lapangan merupakan perpaduan antara aspek yang dinilai oleh ahli modul dan ahli materi. Hasil validasi modul oleh praktisi lapangan menunjukkan nilai kelayakan modul untuk seluruh aspek sebesar $98,1 \%$ dengan kriteria sangat layak. Hasil validasi praktisi lapangan ditampilkan pada tabel 5.

Tabel 5. Hasil Validasi Modul oleh Praktisi Lapangan

\begin{tabular}{clcc}
\hline No. & \multicolumn{1}{c}{ Aspek yang Dinilai } & Persentase & Kriteria \\
\hline 1. & Komponen Modul & $100 \%$ & Sangat Layak \\
2. & Karakteristik Modul & $98,18 \%$ & Sangat Layak \\
3. & Penyajian Modul & $93,33 \%$ & Sangat Layak \\
4. & Organisasi Materi & $100 \%$ & Sangat Layak \\
5. & Cakupan dan Akurasi Materi & $100 \%$ & Sangat Layak \\
6. & Materi Kontektual & $100 \%$ & Sangat Layak \\
7. & Kesesuaian dengan model SQ4R & $100 \%$ & Sangat Layak \\
\hline & Jumlah & $98,1 \%$ & Sangat Layak \\
\hline
\end{tabular}

\section{Respons Siswa terhadap Modul}

Siswa memberikan respons yang sangat baik (94,96\%). Hasil tersebut menunjukkan bahwa modul bersifat praktis untuk digunakan. Hasil respons siswa selengkapnya ditampilkan pada tabel 6.

Tabel 6. Hasil Respon Siswa terhadap Modul

\begin{tabular}{cccccc}
\hline No Siswa & Respon $(\%)$ & Kriteria & No Siswa & Respon (\%) & Kriteria \\
\hline 1. & 91.11 & Sangat Baik & 9 & 100.00 & Sangat Baik \\
2. & 80.00 & Baik & 10 & 100.00 & Sangat Baik \\
3. & 77.78 & Baik & 11 & 100.00 & Sangat Baik \\
4. & 95.56 & Sangat Baik & 12 & 100.00 & Sangat Baik \\
5. & 97.78 & Sangat Baik & 13 & 100.00 & Sangat Baik \\
6. & 95.56 & Sangat Baik & 14 & 100.00 & Sangat Baik \\
7. & 97.78 & Sangat Baik & 15 & 100.00 & Sangat Baik \\
\cline { 4 - 6 } 8. & 88.89 & Sangat Baik & Jumlah & $\mathbf{9 4 , 9 6 \%}$ & Sangat Baik \\
\hline
\end{tabular}

\section{PEMBAHASAN}

Produk yang dikembangkan yakni modul SQ4R. Modul pembelajaran merupakan bahan ajar yang disusun secara sistematis, mencakup metode, materi, dan evaluasi untuk mencapai kompetensi secara mandiri (Purwanto, 2007; Anwar, 2010). Modul yang layak digunakan dalam mendukung kegiatan pembelajaran adalah modul yang memenuhi kriteria self instructional, self contained, stand alone, adaptive, dan user friendly (Depdiknas, 2008). Modul yang dikembangkan memenuhi kriteria layak dengan perolehan nilai kelayakan modul sebesar $85,45 \%$ dari ahli bahan ajar. Perolehan nilai kelayakan modul ini menunjukkan bahwa modul telah memenuhi kriteria layak. Modul yang dikembangkan memenuhi kriteria self instructional ditunjukkan dari perolehan nilai kelayakan aspek self instructional sebesar 85,71\%. Modul dapat memenuhi kriteria tersebut karena dilengkapi dengan petunjuk penggunaan, kompetensi, dan tujuan pembelajaran. Petunjuk penggunaan modul disajikan dengan tujuan untuk 
memudahkan siswa memahami langkah-langkah operasional dalam menggunakan modul. Tahapan pembelajaran yang sistematis dapat meningkatkan keterlibatan siswa dalam pembelajaran (Ahmad \& Mahmood, 2010). Keterlibatan aktif dalam proses pembelajaran dapat membantu siswa mengonstruksi pengetahuan dan mengembangkan keterampilan secara mandiri (Santrock, 2010). Kompetensi dan tujuan pembelajaran disajikan dalam modul dengan tujuan untuk mengarahkan siswa mengikuti proses pembelajaran dengan baik untuk mencapai kompetensi yang diharapkan (Hamalik, 2011). Dengan demikian, penyajian petunjuk penggunaan, kompetensi, dan tujuan pembelajaran di dalam modul yang dikembangkan dapat memfasilitasi siswa belajar mandiri (self instruction).

Penggunaan modul sebagai bahan belajar mandiri juga didukung dengan adanya kegiatan pembelajaran yang disusun sistematis. Kegiatan pembelajaran pada modul disesuaikan dengan tahapan model SQ4R yang terdiri dari enam tahap. Pembelajaran dengan model SQ4R dapat mendorong siswa aktif dalam belajar (Rustina, 2014; Shoimin, 2014; Rahayu dkk., 2015; Rasjid, 2015; Swari dkk., 2016; Wulandari dkk., 2016; Rivan dkk., 2017) melalui kegiatan merumuskan pertanyaan, mencari jawaban atas pertanyaannya sendiri, dan mengungkapkan ide (Shoimin, 2014; Wulandari dkk., 2016; Rivan dkk., 2017). Siswa aktif dalam pembelajaran akan belajar dengan baik sehingga dapat mengonstruksi pengetahuan dan mengembangkan keterampilan secara mandiri (Santrock, 2010; Arends, 2012). Semua hasil pembelajaran siswa tercatat dalam modul sehingga memudahkan siswa untuk mempelajari konsep kembali.

Penyajian materi dalam modul penting untuk dinilai kelayakannya karena materi berperan memfasilitasi siswa membangun pengetahuan dan mengembangkan keterampilan (UNESCO, 2019). Kelayakan materi dalam modul untuk seluruh aspek diperoleh nilai sebesar 97,5\%, artinya penyajian materi dalam modul yang dikembangkan memiliki kriteria sangat layak. Kelayakan materi didukung dengan kesesuaiannya dengan kompetensi dasar. Materi yang sesuai dengan kompetensi dasar dimaksudkan agar siswa dapat mempelajari materi dengan tuntas. Penyajian materi dalam modul dibagi dalam serangkaian kegiatan belajar untuk mencapai KD 3.4 yang berkaitan dengan jaringan hewan, KD 3.5 yang berkaitan dengan sistem gerak, dan KD 3.6 yang berkaitan dengan sistem peredaran darah. Modul yang menyajikan materi sesuai dengan kompetensi dasar memenuhi kriteria modul yakni self contained (Depdiknas, 2008).

Materi dalam modul disesuaikan dengan perkembangan ilmu dan teknologi sehingga memfasilitasi siswa mampu mengaitkan materi yang dipelajari dengan kajian bidang ilmu yang lain. Penyajian materi yang dikaitkan dengan perkembangan ilmu dan teknologi disusun dalam bentuk informasi khusus pada bagian “Tahukah Kamu?” berisi informasi terbaru tentang materi, kelainan yang mungkin terjadi, dan teknologi yang berkaitan dengan materi yang dibahas. Penyajian materi dalam modul yang dikaitkan dengan perkembangan ilmu dan teknologi memenuhi kriteria modul yang bersifat adaptive (Depdiknas, 2008).

Modul yang baik memiliki kriteria stand alone, artinya modul dapat digunakan tanpa bergantung dengan bahan ajar lain (Depdiknas, 2008). Modul yang dikembangkan telah memenuhi kriteria stand alone ditunjukkan dari perolehan nilai kelayakan aspek stand alone sebesar 100\%. Modul yang dikembangkan dapat bersifat stand alone karena terdapat lembar kegiatan belajar siswa, materi, evaluasi, umpan balik, dan glosarium. Lembar kegiatan belajar siswa dapat memudahkan siswa untuk belajar. Evaluasi dan umpan balik dapat memfasilitasi siswa untuk mengukur kompetensi yang dimiliki dan ketercapaiannya. Glosarium dapat memfasilitasi siswa memahami istilah penting sehingga siswa lebih memahami isi materi. Dengan komponen-komponen tersebut, modul dapat dipelajari secara tuntas tanpa bergantung dengan media/bahan belajar lain (Lembaga Administrasi Negara, 2009).

Kelayakan modul sebagai bahan belajar juga didukung oleh penggunaan bahasa yang mudah dipahami sehingga siswa mudah memahami isi yang ada dalam modul. Penggunaan bahasa dikatakan baik dan mudah dipahami apabila sesuai dengan PUEBI, bersifat komunikatif, konsisten dalam penggunaan kata dan istilah, serta tidak menimbulkan makna ganda. Penggunaan bahasa yang mudah dipahami memenuhi kriteria modul yang bersifat user friendly (Depdiknas, 2008). Modul yang layak juga dilihat dari kemudahan modul dalam menunjang proses pembelajaran biologi (Akker dkk., 2013). Hasil validasi modul oleh praktisi lapangan menunjukkan nilai kelayakan modul untuk seluruh aspek sebesar 98,1\% dengan kriteria sangat layak untuk mendukung proses pembelajaran. Modul dapat menunjang proses pembelajaran karena dilengkapi komponen-komponen modul yang disusun secara sistematis sehingga memudahkan siswa belajar mandiri. Modul pembelajaran disusun dengan baik sehingga dapat menarik perhatian siswa (Permatasari dkk., 2016; Syafi'i dkk., 2016). Modul yang menarik dapat mendorong rasa ingin tahu (Setiyaningsih dkk., 2015; Permatasari dkk., 2016) dan meningkatkan motivasi siswa (Ditasari dkk., 2013; Irwan dkk., 2014; Permatasari dkk., 2016) sehingga siswa terlibat aktif dalam pembelajaran. Keterlibatan siswa dapat membantu siswa mengembangkan kompetensi yang dimiliki (Santrock, 2010).

Modul yang praktis digunakan juga dilihat dari respons siswa saat menggunakan modul. Siswa memberikan respons yang sangat baik, yakni dengan perolehan nilai sebesar 94,96\%. Perolehan hasil ini didukung karena modul yang dikembangkan berupa modul cetak sehingga mudah digunakan untuk proses belajar kapanpun dan dimanapun. Modul juga dapat digunakan tanpa peralatan khusus sehingga dapat digunakan oleh semua kalangan siswa. Modul dapat digunakan dengan mudah juga karena adanya petunjuk penggunaan sehingga dapat dipelajari dengan baik (Arsyar, 2012; Sanjaya, 2012; Irwan dkk., 2014). Modul juga mudah disimpan dan dibawa karena dibagi menjadi tiga jilid sesuai dengan materi yang dibahas sehingga memudahkan dalam mendukung kegiatan pembelajaran (Suparmin, 2012). 


\section{SIMPULAN}

Produk modul SQ4R layak dan praktis digunakan sebagai bahan belajar siswa. Modul layak karena telah memenuhi karakteristik modul yakni self instructional, self contained, stand alone, adaptive, dan user friendly. Modul memperoleh nilai kelayakan dari ahli bahan ajar sebesar 85,45\% dengan kriteria layak, dari ahli materi sebesar 97,5\% dengan kriteria sangat layak, dan dari praktisi lapangan sebesar 98,1\% dengan kriteria sangat layak serta respons siswa yang sangat baik dengan perolehan nilai sebesar $94,96 \%$.

\section{DAFTAR RUJUKAN}

Ahmad, Z. \& Mahmood, N. (2010). Effect of Cooperative Learning vs Traditional Instruction on Prostective Teachers's Learning Experience and Achievement. Journal of Faculty of Educational Sciences, 43(1), 151-164.

Akbar, S. (2013). Instrumen Perangkat Pembelajaran. Bandung: Remaja Rosdakarya.

Akker, J., Bannan, B., Kelly., A. E., Nieveen, N., \& Plomp, T. (2013). Educational Design Research Part A: An Introduction. Netherlands: SLO.

Anwar, I. (2010). Pengembangan Bahan Ajar. Bandung: Direktori UPI.

Arends, R. (2012). Learning to Teach, Ninth Edition. New York: McGraw-Hill.

Arhasy, E. A. R., Rustina, R., \& Heryani, Y. (2015). Kontribusi Pembelajaran Kontekstual dengan Teknik SQ4R terhadap Peningkatan Kemampuan Pemahaman dan Berpikir Kritis Matematis. Jurnal Siliwangi, 1(1).

Branch, R. M. (2009). Instructional Design: The ADDIE Approach. New York: Springer.

Departemen Pendidikan Nasional. (2010). Teknik Penyusunan Modul. Jakarta: Direktorat Jenderal Manajemen Pendidikan Dasar dan Menengah.

Dewi, K. C. (2016). Peningkatan Aktivitas dan Hasil Belajar Sistem Ekskresi melalui Penerapan Model Pembelajaran SQ4R bagi Siswa Kelas XI IPA 1 SMA Negeri 1 Cepiring Semester II Tahun Pelajaran 2015/2016. Majalah Ilmiah Inspiratif, 2(2).

Ditasari, R., Peniati, E., \& Kasmui. (2013). Pengembangan Modul Pembelajaran IPA Terpadu Berpendekatan Keterampilan Proses pada Tema Dampak Limbah Rumah Tangga terhadap Lingkungan untuk SMP Kelas VIII. Unnes Science Education Journal, 2(1), 32-336.

Hamalik, O. (2011). Perencanaan Pengajaran Berdasarkan Pendekatan Sistem. Jakarta: Bumi Aksara.

Irwan., Ningsih, K., \& Marlina, R. (2014). Pengaruh Modul terhadap Hasil Belajar Siswa pada Materi Keanekaragaman Hayati SMA Negeri 9 Pontianak. Jurnal Pendidikan dan Pembelajaran, 3(9).

Mulyasa, E. (2006). Kurikulum Berbasis Kompetensi. Bandung: Remaja Rosdakarya.

Permatasari, P. A., Dwiastuti, S., \& Suwarno. (2016). Pengaruh Penggunaan Modul Berbasis Guided Inquiry terhadap Peningkatan Motivasi Belajar dan Kemampuan Berpikir Kritis Siswa. Proceeding Biology Education Conference, 13(1), $318-324$.

Purwanto., Rahadi, A., \& Lasmono, S. (2007). Pengembangan Modul. Jakarta: Depdiknas Pustekom.

Rahayu, P. I. W., Zulaikha, S., \& Negara, I. G. A. O. (2014). Model Pembelajaran Kooperatif Tipe SQ4R Berbasis Keterampilan Proses Berpengaruh terhadap Hasil Belajar IPA Siswa Kelas V SD Gugus Letkol Wisnu. Jurnal Mimbar PGSD Universitas Pendidikan Ganesha, 2(1).

Rasjid, Y. (2015). Pengaruh Model Pembelajaran Survey Question Read Reflect Recite Review (SQ4R) dengan Metode Talking Stick terhadap Keterampilan Metakognisi dan Hasil Belajar Biologi Siswa SMAN 9 Makassar. Jurnal Biotek, 3(1), 170183.

Rivan, O. F., Suharto., \& Chuinda, N. (2017). The Application of Learning Model SQ4R (Survey, Question, Read, Reflect, Recite, Review) can Increase Activeness and Learning Outcomes of Student. Jurnal Pendidikan Bisnis dan Manajemen, 3(1), 35-45.

Rustina, R. (2014). Pengaruh Penggunaan Pembelajaran Kontekstual dengan Teknik SQ4R terhadap Peningkatan Kemampuan Pemahaman dan Berpikir Kritis Matematis Siswa SMP Negeri 8 Kota Tasikmalaya. Jurnal Pendidikan dan Keguruan, $1(1)$.

Sanjaya, W. (2012). Media Komunikasi Pembelajaran. Jakarta: Kencana Prenada Media Group.

Santrock. (2010). Educational Psychology, $5^{\text {th }}$ Edition. New York: McGraw-Hill.

Setiyaningsih, I. Nugroho, A. S., \& Prasetiyo. (2015). Pengaruh Penggunaan Modul Berbasis Masalah dalam Pembelajaran Inquiry terhadap Curiosity dan Hasil Belajar Siswa Pokok Bahasan Sistem Koordinasi Kelas XI SMAN 1 Kayen. Prosiding Seminar Nasional Sains \& Entrepreneurship II, 333-341.

Suparmin, Bakar, U. A., Giyoto, \& Fauzi, A. (2012). Validitas, Reliabilitas, dan Kepraktisan Ujian melalui Observasi dan Bentuk Lisan bagi Kelas Besar Pada Prodi PAI Fakultas Tarbiyah dan Bahasa IAIN Surakarta. Kodifikasia, 6(1), 65-76.

Swari, F.D.R., Sari, M.S., \& Susilowati. (2016). Pengaruh Inkuiri Terstruktur Berbasis SQ4R (Survey, Question, Read, Reflect, Recite, and Review) terhadap Pemahaman Membaca (Reading Comprehension) dan Hasil Belajar Siswa di SMPN 19 Malang. Pendidikan Hayati, 1(1). 
Syafi'i, W., Sari, R. F., \& Arnetis. (2016). Meningkatkan Kemampuan Berpikir Kritis Siswa pada Materi Sistem Sirkulasi Kelas XI melalui Pengembangan Modul Pembelajaran Berorientasi Model Guided Inquiry. Jurnal Biogenesis, 13(1), 77 -84.

UNESCO. (2019). Supplementary Learning and Teaching Materials. Learning Portal: UNESCO's International Institute for Educational Planning. (Online), (https://learningportal.iiep.unesco.org/), diakses tanggal 22 Februari 2019.

Wulandari, S., Budiyono, \& Iswahyudi, G. (2016). Eksperimentasi Model Pembelajaran Survey, Question, Read, Recite, Review (SQ3R) dan Survey, Question, Read, Reflect, Recite, Review (SQ4R) Ditinjau dari Jenis Kelamin dan Gaya Belajar. Jurnal Elektronik Pembelajaran Matematika, 4(1), 34- 47. 